University of Nebraska - Lincoln

DigitalCommons@University of Nebraska - Lincoln

USDA Wildlife Services - Staff Publications

U.S. Department of Agriculture: Animal and Plant Health Inspection Service

February 2006

\title{
Immunocontraception of Florida Feral Swine with a Single-dose GnRH Vaccine
}

G. Killian

Almquist Research Center, Pennsylvania State University

L. Miller

National Wildlife Research Center, USDA-APHIS

J. Rhyan

National Wildlife Research Center, USDA-APHIS

H. Doten

USDA-APHIS

Follow this and additional works at: https://digitalcommons.unl.edu/icwdm_usdanwrc

Part of the Environmental Sciences Commons

Killian, G.; Miller, L.; Rhyan, J.; and Doten, H., "Immunocontraception of Florida Feral Swine with a Singledose GnRH Vaccine" (2006). USDA Wildlife Services - Staff Publications. 108.

https://digitalcommons.unl.edu/icwdm_usdanwrc/108

This Article is brought to you for free and open access by the U.S. Department of Agriculture: Animal and Plant Health Inspection Service at DigitalCommons@University of Nebraska - Lincoln. It has been accepted for inclusion in USDA Wildlife Services - Staff Publications by an authorized administrator of DigitalCommons@University of Nebraska - Lincoln. 


\title{
Immunocontraception of Florida Feral Swine with a Single-dose GnRH Vaccine
}

\author{
G. Killian ${ }^{1}$, L. Miller ${ }^{2}$, J. Rhyan ${ }^{2}$, H. Doten ${ }^{3}$ \\ ${ }^{1}$ Almquist Research Center, The Pennsylvania State University, University Park, PA; \\ ${ }^{2}$ National Wildlife Research Center, USDA-APHIS, Ft. Collins, CO; \\ ${ }^{3}$ USDA-APHIS-VS, Gainesville, FL, USA
}

Keywords

Brucellosis and pseudorabies control, contraceptive vaccine, feral swine, population reduction

\section{Correspondence \\ Gary Killian, Almquist Research Center, The Pennsylvania State University, University Park, PA 16802, USA. \\ E-mail: gkillian@psu.edu}

Submitted August 12, 2005;

accepted February 7, 2006.

\section{Citation}

Killian G, Miller L, Rhyan J, Doten H. Immunocontraception of Florida feral swine with a single-dose $\mathrm{GnRH}$ vaccine.

Am J Reprod Immunol 2006; 55:378-384

doi:10.1111/j.1600-0897.2006.00379.x

\section{Problem}

Methods to limit fertility of feral swine are needed to reduce transmission of diseases and agricultural and ecosystem damage.

\section{Method of Study}

We evaluated a single-shot GnRH immunocontraceptive vaccine in both male and female feral swine for its effect on fertility and functional status of the reproductive tissues. Captive feral pigs were randomly assigned to receive 1000 or $2000 \mu \mathrm{g}$ GnRH-KLH vaccine treatments or no treatment.

\section{Results}

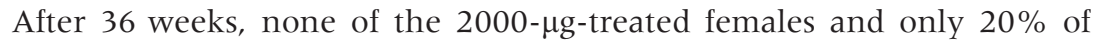

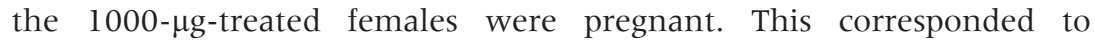
reduced serum progesterone, regressed tissues within the reproductive tract and lack of evidence for follicular development leading to ovulation. Males were less responsive to the vaccine than females, but more responsive to the lower dose of the vaccine than the higher dose.

\section{Conclusions}

The single-shot GnRH vaccine is effective in controlling fertility of female feral swine and may be useful for population reduction.

\section{Introduction}

Populations of feral swine (Sus scrofa) have been reported for 23 states with the total population estimated to be 3 million animals. ${ }^{1,2}$ Although recreational hunting of feral swine is popular in in some states, overabundance of feral swine is a problem that raises concerns relating to ecosystem and agricultural damage, and of disease threat to wildlife, domestic livestock and humans.

Feral swine are known reservoirs for both brucellosis and pseudorabies. Swine brucellosis is caused by the bacterium Brucella suis and is characterized by abortion, infertility, lameness, and vulval discharges in infected animals. ${ }^{3}$ The afterbirth of Brucella-infec- ted pigs may also transmit the disease to cattle. ${ }^{4,5}$ Humans are also susceptible to swine brucellosis, putting persons who come in contact with feral swine at risk. Pseudorabies is a highly contagious herpes viral disease which occurs in swine. The virulence of the feral swine pseudorabies strain is considerably less than that of the strain isolated from domestic pigs. $^{2}$ However, once swine are infected with the virus they will remain infected for the rest of their lives, although they may not show clinical signs of the disease. Swine infected with pseudorabies are capable of transmitting the disease to other species including cattle, sheep, goats, horses, dogs, and cats. Pseudorabies infections in these secondary species are usually fatal. 
Control of fertility of overabundant wildlife and feral species is a topic that has received considerable attention in recent years. ${ }^{6}$ Immunocontraceptive vaccines have been the focus of much infertility research with the goal of population management being a single-dose, long-acting contraceptive that is highly effective with minimal adverse effects. Research on an immunocontraceptive vaccine of particular interest for swine targets gonadotropin-releasing hormone (GnRH). Several short-term investigations have studied GnRH vaccines for commercial swine production with an interest in using the approach as an alternative to surgical castration of boars. ${ }^{7-9}$ The GnRH vaccine stimulates antibody production to inactivate endogenous GnRH, and thereby reduces release of gonadotrophic hormones leading to gonadal atrophy. ${ }^{10}$ As a result, regression or lack of development of the reproductive organs results in 'immunological castration'. Although evidence from other species suggests that the vaccine is effective in both males and females, and produces both infertility and cessation of sexual activity, studies with swine have primarily focused on evaluating the effects of the vaccine in males. Recently, however, we demonstrated that a single-shot GnRH vaccine developed at the National Wildlife Research Center, USDA-APHIS was 80-90\% effective in preventing estrus behavior and pregnancy in domestic pigs. ${ }^{11}$

Evidence suggests that among feral swine, oral contact with reproductive discharges and sexual activity are the primary means of transmission of both brucellosis ${ }^{4}$ and pseudorabies. ${ }^{12}$ Our interest in evaluation of a GnRH immunocontraceptive vaccine for feral swine is based on recent studies with deer and domestic pigs in which we demonstrated that both fertility and reproductive behavior are greatly diminished. ${ }^{11,13}$ We believe that the GnRH vaccine represents a potentially ideal contraceptive vaccine for feral swine because it induces infertility in both sexes and limits the spread of brucellosis and pseudorabies by limiting sexual activity.

Although we have demonstrated the effectiveness of our GnRH vaccine in domestic swine, ${ }^{11}$ we were also interested in establishing the efficacy of the vaccine in a mixed feral population of different size males and females, including pregnant, non-pregnant and breeding animals, as this is more typical of what would be encountered in the field. Therefore, the present study was undertaken to evaluate a single-shot GnRH vaccine in both male and female feral swine for its effect on fertility and status of the reproductive tissues. This effort represents the first step in developing a strategy to use the vaccine to limit fertility and reproductive behavior as a means to reducing the transmission of brucellosis and pseudorabies among feral swine.

\section{Materials and Methods}

Male and female feral swine of unknown history were captured throughout Florida in January-March of 2002. The animals were brought to a farm near Trenton, Florida where they were tested for pseudorabies and brucellosis and dewormed. Animals which tested positive for brucellosis and pseudorabies were not used in the study. Some of the female pigs were pregnant when they were captured. Although the weights of the animals were not taken, the range was estimated to be $7-32 \mathrm{~kg}$. Pigs were maintained for the entire study in outdoor pens located in a shaded, sandy area. The study was approved by the Institutional Animal Care and Use Committee of the Pennsylvania State University.

The GnRH vaccine and adjuvant used were developed at the National Wildlife Research Center and were previously evaluated in white-tailed deer. ${ }^{13}$ The vaccine consisted of the GnRH peptide conjugated to keyhole limpet hemocyanin used in combination with AdjuVac ${ }^{\mathrm{TM}}$ adjuvant (National Wildlife Research Center, USDA-APHIS, Ft. Collins, CO, USA). The adjuvant contained a modified Johne's vaccine, Mycopar $^{\text {TM }}$ (Ft. Dodge Animal Health, Overland Park, KS, USA), as a replacement for Freund's adjuvant.

Male and female pigs were randomly assigned to 1000- or 2000- $\mu \mathrm{g}$ GnRH-KLH vaccine treatment or no treatment. Eleven females received the 1000- $\mu \mathrm{g}$ dose, nine females received the 2000- $\mu$ g dose and five females were untreated. Ten males received the $1000-\mu \mathrm{g}$ dose, 10 males received the 2000- $\mu \mathrm{g}$ dose and four males were untreated.

At the beginning of the study, blood samples were taken and the pigs were immunized with the GnRH vaccine by an intramuscular injection in the rump. Males and females were separated, and large and small pigs of each sex were further sorted into separate pens. Approximately 12 weeks after immunization, blood samples were taken and both treated and untreated males and females were combined together into two large breeding pens where they remained for the duration of the study. Each pen contained both treated and untreated males and female for the remainder of the study. Although 
there was no designated observation period, breeding activity was recorded if it was observed. Sows giving birth during the study were noted, as was the pregnancy status of the females at the end of the study. During the study, two females assigned to the 1000- $\mu$ g treatment and one male assigned to the 2000- $\mu$ g treatment died. In addition, two females and one male in the control groups died. There was no evidence that the deaths were related to the treatments.

In mid-December, 36 weeks after immunization, pigs were killed, a blood sample was taken and the ovaries and testes were recovered. The gonads were weighed and a sample of tissue was fixed in $10 \%$ formalin- $\mathrm{Ca}^{++}$and later prepared for histological evaluation. For a few animals in each treatment, tissue samples of uterus, oviduct, and epididymis were also collected for histological evaluation. Blood samples were used to assay antibody titers for GnRH and testosterone and progesterone.

Histological evaluations were made on coded slides. In males, the testis was evaluated for the presence of cell types associated with spermatogenesis including spermatogonia, primary spermatocytes, round spermatids and elongated spermatids. The functional state of the Leydig cells and the presence of spermatozoa in the epididymis were also considered. For females, the ovaries were examined for stages of follicular development and presence of corpora lutea. Uterus and oviduct samples were examined to determine whether the epithelia lining the uterine and oviduct lumen were active or regressed.

Differences among treated and untreated groups were assessed by least significant difference tests ${ }^{14}$ for multiple comparisons at $P<0.05$.

\section{Results}

Antibody titers for GnRH were negative in preimmunization samples and in all samples taken from untreated pigs. For males, antibody titers were greatest 12 weeks after immunization with either the 1000- or 2000- $\mu$ g dose vaccine (Fig. 1), although titers for both doses declined after 36 weeks. Values for males receiving the 1000- $\mu$ g dose were greater than those receiving the 2000- $\mu \mathrm{g}$ dose at both time points, but were only significant at 36 weeks. In contrast, females receiving either the 1000- or 2000- $\mu$ g dose had similar titers at 12 weeks, but those receiving the 2000- $\mu$ g dose significantly greater titers at 36 weeks than those receiving $1000 \mu \mathrm{g}$ of GnRH (Fig. 1).

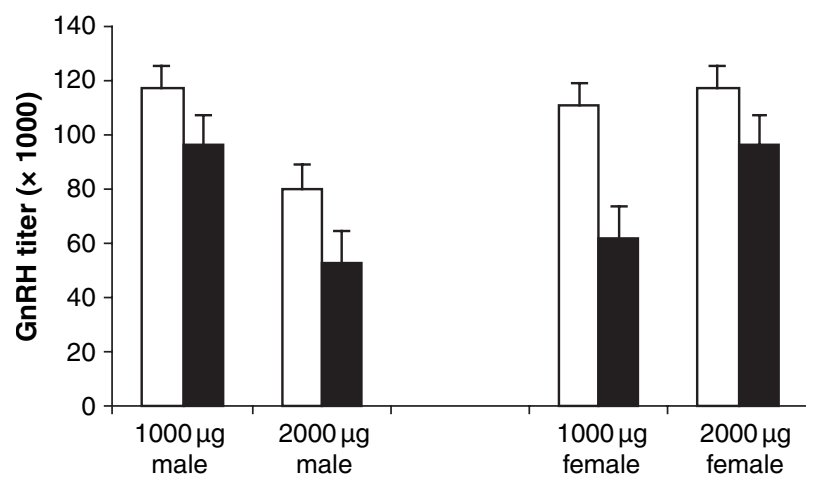

Fig. 1 Serum antibody titers at 12 weeks (open bars) and 36 weeks (solid bars) post-immunization of male $(n=10)$ and female $(n=9)$ feral pigs receiving a single intramuscular injection of either a 1000 or $2000 \mu \mathrm{g}$ dose of $\mathrm{GnRH}$ vaccine. Data are not shown for serum titers of untreated pigs ( $n=5)$, which were all negative.

Average serum progesterone concentrations for all females were $\leq 6 \mu \mathrm{g} / \mathrm{ml}$ at the initial bleed and 12 weeks thereafter. After 36 weeks, average serum progesterone concentrations were also $<6 \mu \mathrm{g} / \mathrm{ml}$ for the treated females, and were significantly less than untreated females which averaged $32 \mu \mathrm{g} / \mathrm{ml}$ of progesterone at 36 weeks. Progesterone values for untreated females corresponded with the percentage of females within each treatment group having corpora lutea in ovaries collected at the end of the study (Fig. 2). Treated females had considerably fewer corpora lutea than control females.

Average serum testosterone concentrations were similar for all groups of males at the start of the study. However, serum testosterone concentrations were significantly less than those of untreated males

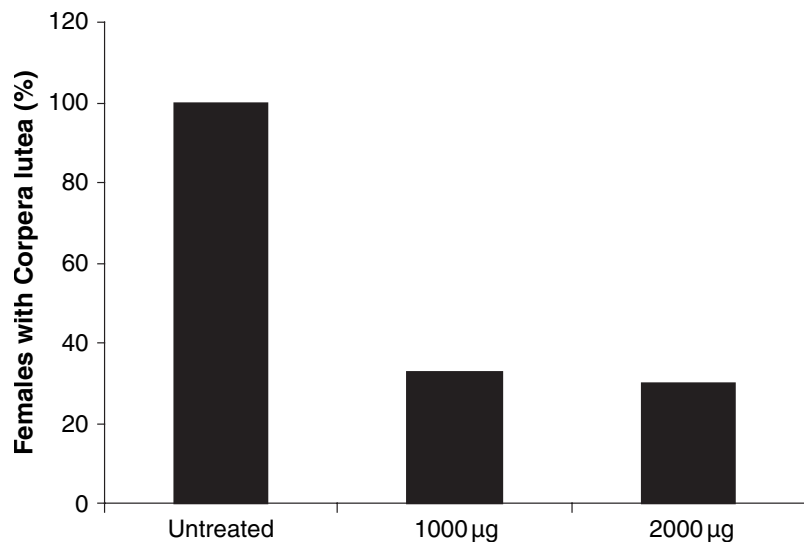

Fig. 2 Percentage of females with ovaries containing corpora lutea in the untreated $(n=3), 1000 \mu \mathrm{g}(n=9)$ and $2000 \mu \mathrm{g}(n=8)$ treatment groups. 
at both 12 and 36 weeks for males receiving either 1000 or $2000 \mu \mathrm{g}$ of GnRH (Fig. 3). However, testis weight at 36 weeks was only significantly lower in males receiving the 1000- $\mu$ g dose (Fig. 4).

Testis tissue from untreated males contained all cell types associated with normal spermatogenesis. In the 1000- $\mu$ g group, Leydig cells were regressed in four of the 10 males examined, while only two of

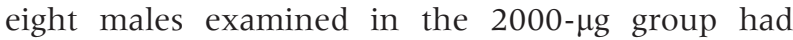
regressed Leydig cells. No males in the 2000- $\mu \mathrm{g}$ group and only three of 10 males $(30 \%)$ in the $1000-\mu \mathrm{g}$ showed a negative effect on primary sper-

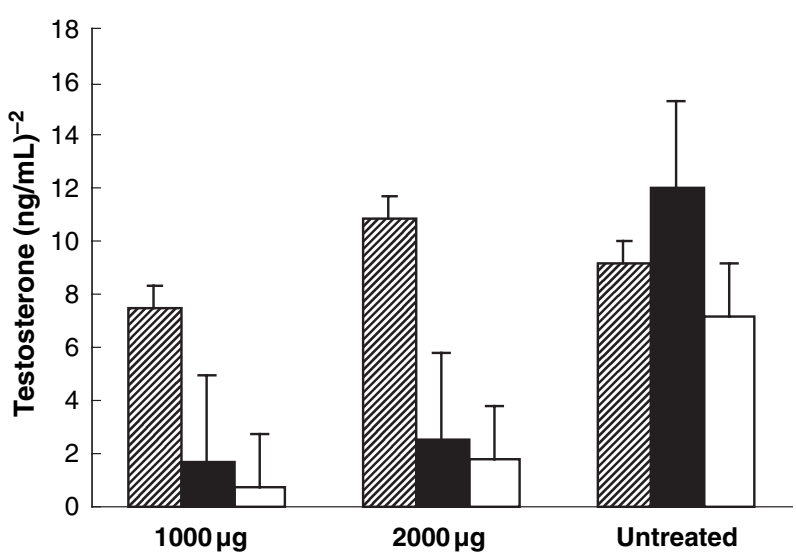

Fig. 3 Plasma testosterone concentrations at the start of the study (striped bars) and at 12 weeks (solid bars) and 36 weeks (open bars) post-immunization. For the $1000 \mu \mathrm{g}, n=10$ for each time point. For the 2000- $\mu$ g group $n=8$ at the initial and 12 week samples and 7 at the 36-week sampling. For the untreated males, $n=4$ for the initial sample and $n=3$ for the 12- and 36-week samplings. Error bars are mean \pm standard error.

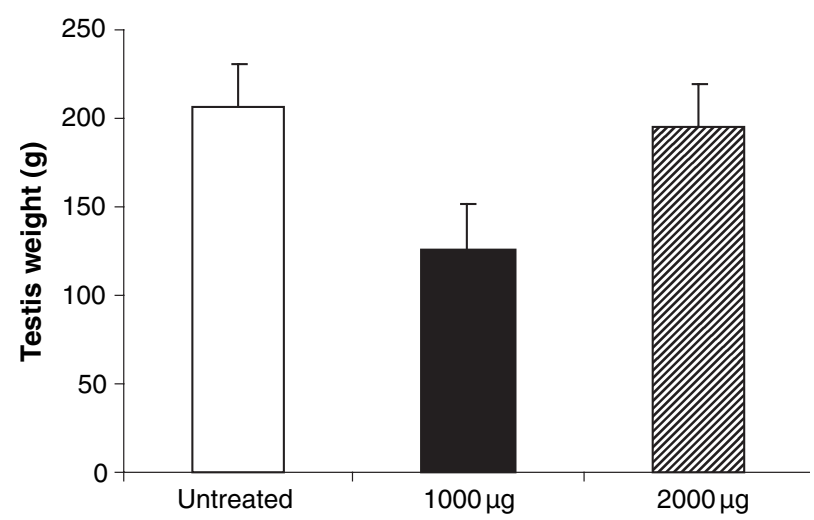

Fig. 4 Testis weights at 36 weeks post-immunization for untreated $(n=3), 1000 \mu \mathrm{g}(n=10)$ and $2000 \mu \mathrm{g}(n=7)$ treated boars. Error bars are mean \pm standard error. matocytes. Four of 10 males $(40 \%)$ in the $1000-\mu \mathrm{g}$ treatment had evidence of a negative effect on round and elongated spermatids, and reduced sperm in the epididymis. However, in the 2000- $\mu$ g group, no males showed a negative impact on round spermatids or epididymal sperm, and only two of seven males $(29 \%)$ had a negative effect on elongated spermatids. These observations are consistent with the conclusion that the lower vaccine dose was more effective in interfering with spermatogenesis than the higher vaccine dose.

Ovarian tissue from untreated females contained primary and tertiary follicles and evidence of recent corpora lutea. Although all females in both treated groups showed evidence of follicular development through the tertiary stage, the majority of these females in both treated groups $(70 \%$ and $67 \%$, respectively) lacked evidence of recent corpora lutea, indicating an absence of recent ovulations (Fig. 2). Although uterine tissue was not recovered from all treated animals, three of five samples recovered from the 1000 - $\mu$ g-treated females $(60 \%)$ and seven of nine samples from the 2000- $\mu$ g-treated females $(78 \%)$ had evidence of regressed uterine epithelia. These observations are consistent with the reduced fertility and the regressed reproductive tracts of the treated females.

Pregnancy status was noted during the study and at slaughter (Fig. 5). All untreated females gave birth

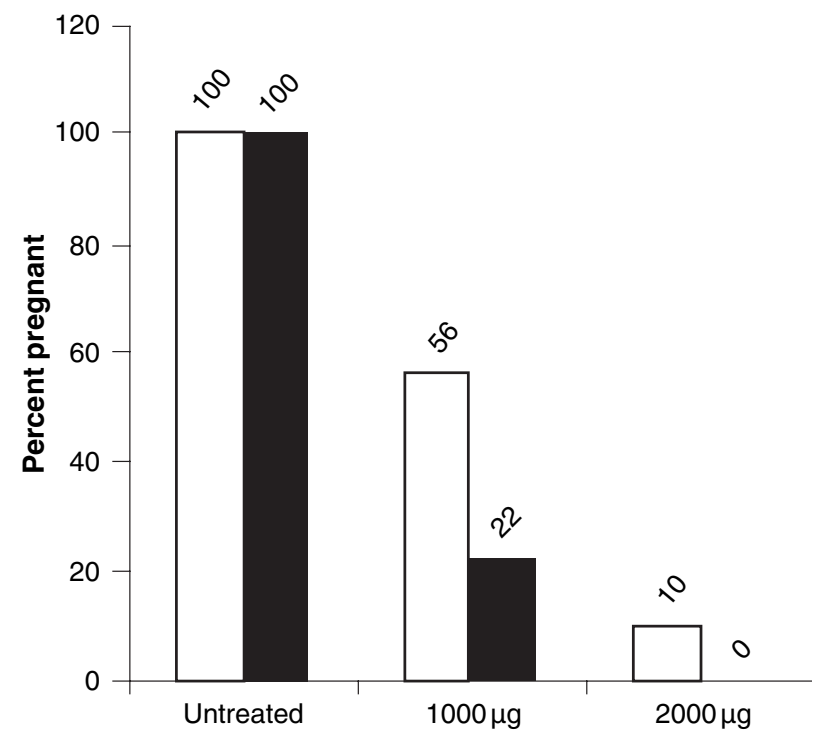

Fig. 5 Percentage females pregnant in untreated $(n=3)$ and $1000 \mu \mathrm{g}$ $(n=9)$ and $2000 \mu \mathrm{g}(n=9)$ treated groups during the study (open bars), and at the conclusion of the study (closed bars). 
sometime during the course of the study $(n=5)$, and all surviving swine were pregnant at slaughter $(n=3)$. In contrast, only $56 \%$ and $10 \%$ of the

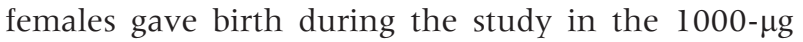
$(n=9)$ and 2000- $\mu \mathrm{g}(n=9)$ treated groups, respectively. Moreover, at slaughter, only $11 \%$ of the females receiving the $1000-\mu \mathrm{g}$ dose $(n=9)$ were pregnant and none of the females receiving the 2000 - $\mu$ g dose $(n=9)$ were pregnant.

\section{Discussion}

GnRH vaccines have been under development and of primary interest for use in several domestic species, including cattle, horses, sheep, as well as swine. ${ }^{15}$ Males have been the primary focus of these studies with an interest in developing a vaccine capable of immunological castration. GnRH vaccines that produce adequate antibody titers are believed to act on the hypothalamus and inhibit synthesis and secretion of GnRH which normally stimulates production of follicle stimulating hormone and luteinizing hormone by the anterior pituitary gland. In the absence of these hormones, normal stimulation of the testes and ovaries is compromised and gonadal regression occurs. In the present study, a singleinjection GnRH-KLH vaccine combined with AdjuVac adjuvant was effective in producing antibody titers that were sufficient to impact several aspects of reproduction in both male and female feral pigs.

In males, the effects included reduced testis weight, reduced plasma testosterone and some histological evidence for effects on spermatogenesis and Leydig cell regression. However, the histochemical analyses suggested that spermatogenesis was disrupted in only a few males as a result of the treatment. A limitation of this study was that it was not possible to actually measure the fertility of individual males, making it difficult to assess the true effect of the vaccine with respect to contraception. In addition, the 36-week study may not have been adequate to assess the full effect of antibody titers on spermatogenesis.

An unexpected result was that the negative effect of the vaccine appeared to be greater in males given

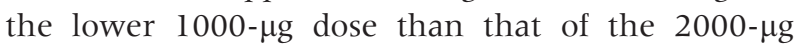
dose during the entire 36-week study. Although difficult to explain, this observation was consistent for all end points measured and was clearly associated with greater antibody titers for males receiving the $1000-\mu g$ dose. Higher titers were associated with greater physiological effects, but not with greater vaccine dose. Under the conditions of this study, it does not appear that either of the GnRH vaccine doses had a clear negative effect on the reproductive physiology of male feral swine. These observations may justify evaluation of additional vaccine doses for males below $1000 \mu \mathrm{g}$, or between 1000 and $2000 \mu \mathrm{g}$ to determine if greater antibody titers and physiological effects can be achieved than were observed in this study.

In contrast to the observations made for males, the GnRH vaccine was highly effective for contraception of females. Contraceptive effects of the singleshot vaccine prevented pregnancy after 36 weeks in all the females receiving the 2000- $\mu \mathrm{g}$ dose, and in $80 \%$ of the females receiving the $1000-\mu \mathrm{g}$ dose. During the study, only one female receiving the higherdose vaccine produced offspring, while $55 \%$ of the females receiving the lower dose had piglets during the 36-week study. Differences observed between the two treatments appear to be related to antiGnRH titers present at slaughter. It is noteworthy that while titers were similar between both treatments 12 weeks after immunization, the higher titer was better sustained after 36 weeks in females receiving the 2000- $\mu \mathrm{g}$ dose.

Because the pregnancy status of the females during the course of the study could only be determined for those that farrowed or were obviously pregnant, it is not possible to know with certainty the mechanism of the anti-fertility effect. Relative to controls, the percentage of females with corpora lutea was considerably less in the treated groups suggesting that fewer ovulations occurred in the treated females leading to a negative effect on fertility. However, as approximately $30 \%$ of the treated females had evidence of recent ovulations at slaughter, and only $22 \%(1000 \mu \mathrm{g})$ and $0 \%(2000 \mu \mathrm{g})$ of the treated females were pregnant at slaughter it is possible that the infertility effect was the result of early embryonic mortality or abortion.

An intriguing observation related to the vaccine doses was that males responded better to the lower dose than the higher vaccine dose, contrary to what was observed for females. Gender differences do exist in the pattern of GnRH and gonadotropic hormone secretion. Non-pregnant females typically have a cyclic pattern of hormone secretion related to the estrous cycle in contrast to males that secrete GnRH at a relatively constant rate. Although the absolute titers of males and females were similar at 
12 weeks, titers of males appeared to decline at 36 weeks while those of females appeared to increase. It is possible that the cyclic pattern of hormone secretion in females served as a periodic 'selfboosting' immunization, resulting in a greater ability to sustain an immune response over time. In addition, with a steady pattern of GnRH secretion in males, it is possible that circulating levels of GnRH antibodies could have been reduced through the formation of antibody-GnRH complexes. Another difference between male and female gamete physiology is that over the period of the female reproductive cycle, 10-20 oocytes are ovulated, whereas in males, literally billions of sperm are produced. These relative differences in the number of gametes produced clearly suggest that the challenge to eliminate or interfere with sperm production is far greater than that for oocyte production.

Evaluation of the injectable single-shot GnRH vaccine in feral swine has shown it to be highly effective in reducing fertility of females for the 36-week study. These observations agree with results obtained with the single-shot GnRH vaccine used on domestic gilts. ${ }^{11}$ In contrast to the study with domestic gilts, however, the feral females treated were comprised of a mixed population of sows and gilts of different sizes and pregnancy status. These findings indicate that the anti-fertility effects of the GnRH vaccine would be broadly effective for treating diverse populations of feral females encountered in the field. Although the vaccine gave less impressive results in males, in practical terms these finding are encouraging because females are the likely target of contraceptive use in the field. An additional beneficial effect of GnRH vaccine use in the field would be the reduction of mating behavior, which would serve to reduce venereal transmission of pseudorabies and brucellosis among feral swine. Because an injectable form of a contraceptive vaccine will have only limited field application for feral swine, emphasis and resources in future research will be directed toward further development of this GnRH vaccine into a form for oral delivery.

\section{Conclusions}

The single-shot GnRH immunocontraceptive vaccine was effective in reducing fertility of a mixed population of male and female feral swine and may be useful for contraception and disease control of feral populations.

\section{Acknowledgments}

We greatly appreciate the assistance provided by $\mathrm{Dr}$ Tommy Dees and David Perry of the Bureau of Animal Disease Control, Florida Department of Agriculture and Consumer Services, Gainesville, FL for providing the feral pigs used in the study and for their help in the collection of data.

\section{References}

1 Conger TH, Young E, Heckmann RA: Brucella suis in feral swine. In: Proceedings of the First National Feral Swine Conference, June 2-3, Ft. Worth, TX, 1999, pp. 98-108.

2 Muller T, Conraths FJ, Hahn EC: Pseudorabies virus infection (Aujesky's disease) in wild swine. Infect Dis Rev 2000; 2: 27-34.

3 Alton GG: Brucella suis. In Animal Brucellosis. K Nielson, JR Duncan, (eds). Boca Raton, CRC Press Inc, 1990, pp. 395-400.

4 Anon: Wild Pigs: Hidden Dangers for Farmers and Hunters. USDA-APHIS Information Bulletin No. 620. 1999, pp 7.

5 Wheeler, CJ: Eradication efforts for brucellosis and pseudorabies. 1999. In: Proceedings of the First National Feral Swine Conference, June 2-3, TX, Ft. Worth, 1999, pp. 86-93.

6 Fagerstone KA, Coffey MA, Curtis PD, Dolbeer RA, Killian GJ, Miller LA, Wilmont, LM: Wildlife Fertility Control, Wildlife Society Technical Review 02-2, pp. 29.

7 Oonk, HB, Turkstra JA, Schaaper W, Erkens MM, Schuitemaker-Deweerd MH, Van Nes A, Verheijden JHM, Meloen RH: New GnRH-like peptide construct to optimize efficient immunocastration of male pigs by immunoneutralization of GnRH. Vaccine 1998; 6:1074-1082.

8 Dunshea FR, Colantoni C, Howard K, McCauly I, Jackson P, Long KA, Lopaticki S, Nugent EA, Simons JA, Walker J, Hennessy DP: Vaccination of boars with a GnRH vaccine (Improvac) eliminates boar taint and increases growth performance. J Anim Sci 2001; 79:2524-2535.

9 Zeng XY, Turkstra JA, Meloen RH, Liu XY, Chen FQ, Schaaper WMM, Oonk HB, Guo DZ, Van De Wiel DFM: Active immunization against gonadotrophinreleasing hormone in Chinese male pig: effects of dose on antibody titer, hormone levels and sexual development. Anim Reprod Sci 2002; 70:223-233.

10 Miller LA, Johns BE, Elias DJ, Crane KA: Comparative efficacy of two immunocontraceptive vaccines. Vaccine 1997; 15:1858-1862. 
11 Miller LA, Rhyan J, Killian G: Evaluation of GnRH contraceptive vaccine using domestic swine as a model for feral hogs. In Proceedings of the 10th Wildlife Damage Management Conference. KA Fagerstone, GW Witmer (eds). Ft. Collins, National Wildlife Research Center, 2003, pp. 120-127.

12 Romano CH, Meade PN, Shultz JE, Chung HY, Gibbs EP, Hahn EC, G. Lo G: Venereal transmission of pseudorabies viruses indigenous to feral swine. $J$ Wildl Dis 2001; 37:289-296.
13 Miller LA, Johns BE, Killian GJ: Immunocontraception of white-tailed deer with GnRH vaccine. Am J Reprod Immunol 2000; 44:266-274.

14 Cochran WG, Cox GM, Experimental Designs. 2nd edn. New York, John Wiley \& Sons, Inc, 1968, pp. 73-76.

15 Thompson DL, Jr: Immunization against GnRH in male species (comparative aspects). Anim Reprod Sci 2000; 60-61. 459-469. 